\title{
Determination of Estrogens in Raw and Treated Wastewater by High- Performance Liquid Chromatography-Ultraviolet Detection
}

\section{Ana Paula Fonseca1, Massano Cardoso2 and Valdemar Esteves3*}

${ }^{1}$ Instituto Politécnico de Coimbra, ESTESC- Coimbra Health School, Farmácia, Rua 5 de Outubro S. Martinho do Bispo Apartado 7006,3040 - 854 Coimbra, Portugal ${ }^{2}$ Faculty of Medicine, University of Coimbra, Rua Larga 3004-504 Coimbra, Portugal

${ }^{3}$ CESAM - Department of Chemistry, University of Aveiro, Campus de Santiago, 3810-193 Aveiro, Portugal

\begin{abstract}
Determination of natural and synthetic estrogens in Waste Water Treatment Plants (WWTP) is fundamental for risk assessment regarding the endocrine disrupting effects in the aquatic environment. A methodology of analysis based on HPLC procedure with UV detection and a C18 analytical column has been developed for the simultaneous determination of estrogens in water samples in less than 9 minutes. The estrogens analysed were estrone, $17 \beta$-estradiol, 17 $\alpha$-ethinylestradiol and estriol. A pre-concentration of the analytes in water samples, was achieved using a SPE procedure with polymeric Strata-X cartridges. Average recoveries of the hormones ranged between $85-120 \%$ of concentrations tested. The use of SPE-HPLC method allows limits of detection of $0.089 \mu \mathrm{g} \mathrm{L}^{-1}$ for estrone, $0.25 \mu \mathrm{g} \mathrm{L}^{-1}$ for estradiol, 0.45 $\mu \mathrm{g} \mathrm{L}^{-1}$ for estriol and $0.11 \mu \mathrm{g} \mathrm{L}^{-1}$ for ethinylestradiol. Samples collected from nine WWTP's raw wastewaters and treated wastewaters located at the Portugal Central Region, were analyzed and the concentrations obtained were in the range of $0.15-0.72 \mu \mathrm{g} \mathrm{L}^{-1}$ for estrone, $0.10-0.51 \mu \mathrm{g} \mathrm{L}^{-1}$ for estradiol, and $0.11-0.23 \mu \mathrm{g} \mathrm{L}^{-1}$ for ethinylestradiol.
\end{abstract}

Keywords: Estrogens; SPE; HPLC-UV; Water analysis; WWTP's raw wastewaters; WWTP's treated wastewaters

\section{Introduction}

During the past few years, there has been a growing concern on possible harmful consequences of exposure to estrogens which are capable of modulating or disrupting the endocrine system [1].

Endocrine disrupting chemicals are of increasing concern due to the risk to human life and to wildlife health. These chemicals include a wide range of compounds such as natural and synthetic estrogens, pharmaceuticals and pesticides. These molecules can disturb the normal activity of the endocrine system, and they have been continuously discharged into the aquatic environment without restrictions. The presence of these compounds in water can cause several adverse effects in the physiology of humans or other organisms in the waters, such as fish [2]. So, recently much research has been done in direct consequence of the occurrence, effects and risks of these compounds. The occurrence and destiny of these compounds in the environment has become a subject of public interest and research [3,4]. Estrogens monitoring in the environment has become of great interest, mainly due to frequent detection in treated wastewaters of Waste Water Treatment Plants (WWTP's), waters for human consumption, rivers and lakes, at concentrations in the range of $\mathrm{ng} \mathrm{L}^{-1}$ to $\mu \mathrm{g} \mathrm{L}^{-1}$. Estrone (E1), $17 \beta$-estradiol (E2) and estriol (E3) are natural female sex hormones produced by humans, mammals and other vertebrates. Ethinylestradiol (EE2) is a synthetic estrogen that has therapeutic uses, such as oral contraceptive (Figure 1) [1,4].

These natural and synthetic estrogens are known to contribute to a large extent of the estrogenicity of WWTP's treated wastewaters; many of their constituents are excreted unchanged as well as metabolites $[5,6]$. WWTP's are large non-linear systems subject to large perturbations in flow and weight, together with uncertainties concerning the composition of the raw wastewater [7-9]. Inactive hormones could be converted back in the environment to their active forms, because they not completely degraded biologically.

The estrogens have been detected in waste waters, surface waters as well as in groundwater, and are considered the most important compounds responsible for the in vitro estrogenic activity of treated wastewaters of domestic WWTP's [9,10]. The decrease of fertilization rate and the alteration of reproductive performance of fishes, as well as various development and reproductive capacities of other aquatic invertebrates have been also reported $[8,10]$. The behaviour and fate of these estrogens depend on its physical-chemical properties and on the environment characteristics $[5,10,11]$.

In order to prevent these uncontrolled effects on human health and

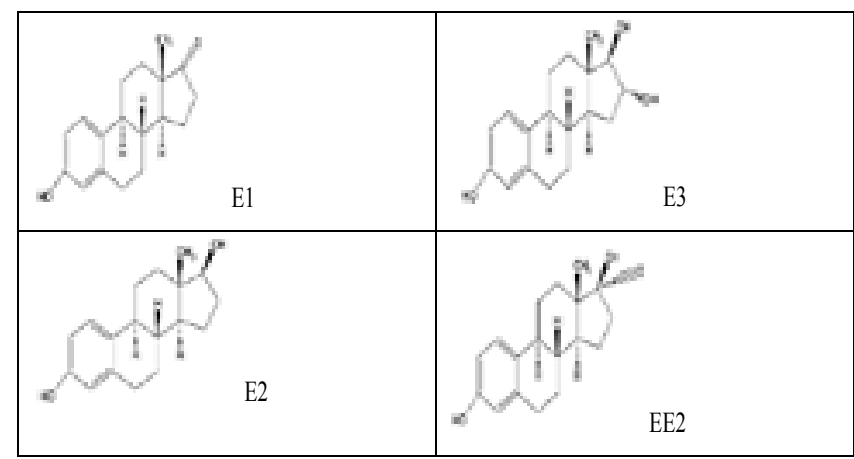

Figure 1: Molecular structure of Estrone (E1), 17ß-Estradiol (E2), Estriol (E3) and $17 \alpha$-Ethinylestradiol (EE2).

*Corresponding author: Valdemar Esteves, CESAM-Department of Chemistry University of Aveiro, Campus de Santiago, 3810-193 Aveiro, Portugal, Tel: +351 239802430; Fax: +351 239813395; E-mail: valdemar@ua.pt

Received October 20, 2013; Accepted December 24, 2013; Published December 27, 2013

Citation: Fonseca AP, Cardoso M, Esteves V (2013) Determination of Estrogens in Raw and Treated Wastewater by High-Performance Liquid ChromatographyUltraviolet Detection. J Environ Anal Toxicol 4: 203. doi: 10.4172/21610525.1000203

Copyright: (c) 2013 Fonseca AP, et al. This is an open-access article distributed under the terms of the Creative Commons Attribution License, which permits unrestricted use, distribution, and reproduction in any medium, provided the original author and source are credited. 
the deleterious effects on the aquatic environment, great importance should be attached to the careful monitoring required for risk assessment and remediation $[12,13]$

In the last few decades, many efforts have been devoted to the development of analytical methodologies for detection of the estrogenic compounds in environmental samples. Accordingly, there is considerable interest in developing sensitive analytical methods applicable to estrogens monitoring. Most methods of determination of emergent contaminants reported in the literature use HPLC-MS, however this technique is expensive comparing to HPLV-UV. HPLC is enabling to determinate estrogenic compounds with limits of detection between 0.3 and $1.1 \mu \mathrm{g} \mathrm{L}^{-1}$ using UV detection [14,15]. Since these pollutants are usually present in aqueous samples at low concentrations levels, a simple extraction and pre-concentration step is needed prior to measurement $[6,16]$.

Solid phase extraction (SPE) is recognized as a very common sample pre-treatment methodology for concentrating the target analytes in biological and environmental samples. SPE coupled with HPLC is an interesting method for determination of trace organic compounds, and combines the advantages of SPE and those of HPLC.

The first aim of this study is to optimize a SPE procedure for cleaning and concentrating samples together with an HPLC methodology for the simultaneous determination of these four estrogens in wastewater samples. The second aim was quantify these estrogens, on nine WWTP's, located at the Portugal Central Region, before discharge into the Rivers.

\section{Experimental}

\section{Instrumentation}

A high-performance liquid chromatographic (HPLC) (Dionex) system equipped with four P680 pumps, an automatic injector ASI100 , a loop of $100 \mu \mathrm{L}$ and a PDA-100 ultraviolet detector was used. All separations were achieved on an analytical reversed phase C18 column (150 mm x $4.6 \mathrm{~mm} \times 5 \mu \mathrm{m}$, Restek Pinnacle, DB) with a mobile phase flow rate of $0.8 \mathrm{~mL} \mathrm{~min}^{-1}$ under isocratic conditions. The mobile phase was a mixture of acetonitrile/water (45:55; v/v). The amount of sample injected was $20 \mu \mathrm{L}$ and the detection wavelength used was $220 \mathrm{~nm}$.

For SPE Visiprep larger volume sampler and visiprep SPE vacuum manifold from Sigma-Aldrich (NSW, Australia) were used.

The Strata-X $33 \mu \mathrm{m}$ Polymeric Reversed Phase Column $(500 \mathrm{mg} / 6 \mathrm{~mL})$ was obtained from Phenomenex (USA).

\section{Chemicals and reagents}

A stock standard solution (0.25 $\left.\mathrm{g} \mathrm{L}^{-1}\right)$ of Estrone (Sigma, 99\%), 17 $\beta$-estradiol(Fluka, 97\%), estriol(Sigma, 99\%) and 17 $\alpha$-ethinylestradiol (Sigma, 98\%) was prepared in acetonitrile (Panreac Química, S.A.). From stock solution, standards with concentrations in the range 0.50 to $10.00 \mathrm{mg} \mathrm{L}^{-1}$ were prepared in water. The solutions were degassed in an ultrasonic bath for 15 min before use, and filtered through a $0.22 \mu \mathrm{m}$ membrane filter prior to analysis in HPLC.

\section{Preparation of WWTP's samples}

Water samples, with a volume of $1000 \mathrm{~mL}$ were collected from the entrance and treated wastewater of nine main WWTP's, three times each and three replicates each), located at the Portugal Central Region, receiving only domestic waters. All WWTP'S studied have secondary treatment: primary treatment is intended to reduce oils, grease, fats, sand, grit, and settle-able solids (this step is done entirely mechanically by means of filtration and sedimentation) and secondary treatment planned to substantially degrade the organic content of the sewage. The organic solids (sludge) are neutralized and then disposed or re-used. The final treated wastewater is discharged into the Rivers. However, WWTP's are non-linear systems subject to great perturbations in flow and weight, together with uncertainties concerning the composition of the raw wastewater.

All water samples were filtered through glass microfiber filter GF/F $55 \mathrm{MM}$ from Whatman with vacuum pump, to eliminate suspended solids, and passed successively though a glass fiber $0.45 \mu \mathrm{m}$ from Millipore, before SPE procedure. Samples were acidified to $\mathrm{pH} 2$ and stored at $4^{\circ} \mathrm{C}$ in the dark. The SPE procedure used for the samples was always carried out within $24 \mathrm{~h}$ after collection to keep microbial degradation to a minimum. After SPE procedure, the eluate was dried and the extract redissolved in $1 \mathrm{~mL}$ of acetonitrile and filtered through a $0.22 \mu \mathrm{m}$ membrane, from Millipore, filter prior to analysis by HPLC.

\section{HPLC-UV analysis}

To optimize the HPLC conditions in order to determine the efficiency of the method, standards of mixtures of the estrogens was analysed. The elution conditions used to separate the compounds gave a good resolution (Figure 2).

The limits of detection (LOD) for each estrogen were determined according with the equations bellow [16]

$$
\begin{aligned}
& y=\mathrm{a}+\mathrm{bx} \\
& \mathrm{LOD}=\mathrm{Y}_{\mathrm{B}}+3 \mathrm{~S}_{\mathrm{B}} \\
& \mathrm{Y}_{\mathrm{B}}=\mathrm{a} ; \\
& \mathrm{S}_{\mathrm{B}}=\mathrm{S}_{\mathrm{y} / \mathrm{x}} \\
& \text { Where: }
\end{aligned}
$$

LOD - value of $y$ at the limit of detection;

$\mathrm{S}_{\mathrm{y} / \mathrm{x}}-$ Standard Deviation in the $\mathrm{y}$-direction

The instrumental LOD obtained were $0.45 \mathrm{mg} \mathrm{L}^{-1}$ for E3, $0.24 \mathrm{mg}$ $\mathrm{L}^{-1}$ for E2, $0.11 \mathrm{mg} \mathrm{L}^{-1}$ for EE2 and $0.089 \mathrm{mg} \mathrm{L}^{-1}$ for E1. The correlation coefficients of the calibration lines were higher than 0.999 .

\section{Optimization of solid-phase extraction procedure}

Five methods of SPE were tested (Table 1). Different types of conditioning and washing of cartridges were tested as well as the $\mathrm{pH}$ of standard solution and the type of solvent to elute. In the five tested

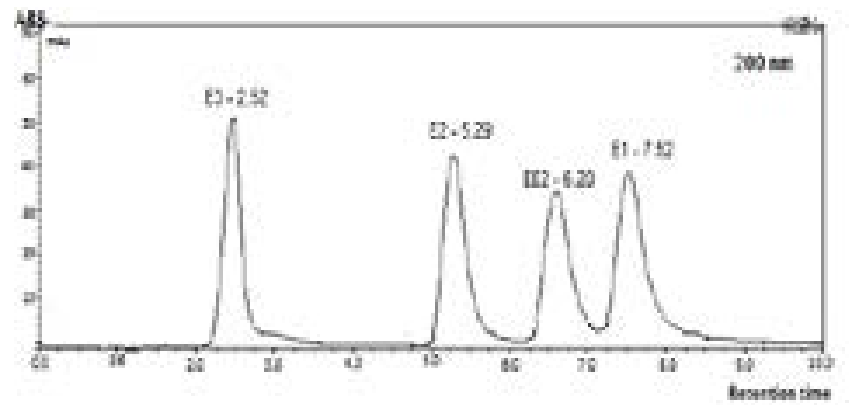

Figure 2: Chromatogram of a standard of the estrogens at concentrations of $10 \mathrm{mg} \mathrm{L}^{-1}$. 
Citation: Fonseca AP, Cardoso M, Esteves V (2013) Determination of Estrogens in Raw and Treated Wastewater by High-Performance Liquid Chromatography-Ultraviolet Detection. J Environ Anal Toxicol 4: 203. doi: 10.4172/2161-0525.1000203

Page 3 of 5

methods, a $1000.0 \pm 0.4 \mathrm{~mL}$ solution standards of estrogens with concentrations of $20 \mu \mathrm{g} \mathrm{L}^{-1}$ each, acidified with hydrochloric acid 0.1 mol L-1, were passed through the cartridges at a flow rate of $4 \mathrm{ml} / \mathrm{min}$ using a pressure of 400 mbar. The choice of $\mathrm{pH}$ value of the solutions used for each method tested was based on references [5,7,16-19]. After elution, samples were dried using vacuum, and then redissolved in 2 $\mathrm{mL}$ of methanol or acetonitrile before analysis.

\section{Results and Discussion}

\section{Recovery of estrogens using the SPE procedure}

SPE recoveries of the four estrogens were calculated by comparing the amounts of estrogens in standards before and after being subjected to SPE procedure (Table 2).

The method 2, at $\mathrm{pH} 2$, was chosen since it showed highest recovery rates, ranging from 100 to $120 \%$ for E1, 85 to $110 \%$ for E2, 90 to $120 \%$ for EE2 and 89.8 to $110 \%$ for E3. In this method the cartridges were conditioned with $5 \mathrm{~mL}$ of methanol, followed by $5 \mathrm{~mL}$ of pure water. A sample of $1000.0 \pm 0.4 \mathrm{~mL}$, acidified at $\mathrm{pH} 2$ with hydrochloric acid 0.1 mol L-1, was passed through a SPE cartridge with a flow rate of $4 \mathrm{~mL} /$ min and a pressure of 400 mbar. Afterwards, $5 \mathrm{~mL}$ of water was used as a cartridge cleanup. The cartridges were dried using vacuum for 2 hours and the elution performed only on the following day.

The elution was performed with $10 \mathrm{~mL}$ of acetonitrile. The eluate was dried completely under vacuum and the extract redissolved in $2 \mathrm{~mL}$ of acetonitrile, filtered through $0.22 \mu \mathrm{m}$ membrane filter and analysed by HPLC.

For recoveries test, distilled water $(1000.0 \pm 0.4 \mathrm{~mL})$ was spiked with the target estrogens in order to obtain, before SPE procedure, initial concentrations of $20 \mu \mathrm{g} \mathrm{L}^{-1}, 10 \mu \mathrm{g} \mathrm{L}^{-1}$ and, $1 \mu \mathrm{g} \mathrm{L} \mathrm{L}^{-1}$ (Table 3). For each concentration, the procedure was repeated three times and analysed by HPLC-UV three times.

Recoveries for the four estrogens were shown to be satisfactory ( $85 \%$ $-120 \%)$ in the range of concentrations tested. The RSD of all recovery experiments was less than $1.47 \%$, with a large replicate of samples $(90 \%)$ with RSD $<0.79 \%$. Correlation coefficients were obtained by plotting the area of the analyte peak versus spiked concentrations obtained (after SPE procedure). The values of correlation coefficients for each estrogen were higher than 0.998 , considered very good.

\section{Analysis of samples from raw wastewater and treated wastewater of WWTP's}

The method SPE-HPLC was applied for the determination of the selected estrogens in nine WWTP's receives domestic waters and discharge treated wastewaters. Results are reported in Table 4. General raw wastewater's estrogens concentrations are in the ranged from, 0.14 to $0.51 \mu \mathrm{g} \mathrm{L}^{-1}$ for estradiol (with a retention time \pm 5.29 ), 0.13 to $0.23 \mu \mathrm{g} \mathrm{L}^{-1}$ for ethinylestradiol (with a retention time \pm 6.20 ) and 0.16 to $0.72 \mu \mathrm{g} \mathrm{L}^{-1}$ for estrone (with a retention time \pm 7.52 ). Treated wastewater's estrogen concentrations are in the ranged from 0.10 to $0.20 \mu \mathrm{g} \mathrm{L}^{-1}$ for estradiol (with a retention time \pm 5.29 ), 0.11 to $0.19 \mu \mathrm{g}^{-1}$ for ethinylestradiol (with a retention time \pm 6.20 ) and 0.15 to $0.25 \mu \mathrm{g} \mathrm{L}^{-1}$ for estrone (with a retention time \pm 7.52 ).

Although the E3 presented a peak in the chromatograms, the small area obtained resulted in a value bellow LOD of respective calibration curve. In order to confirm if each peak area corresponding only to each

\begin{tabular}{|c|c|c|c|c|c|}
\hline & Method 1 & Method 2 & Method 3 & Method 4 & Method 5 \\
\hline Conditioning of cartridges & $\begin{array}{l}2 \times 4 \mathrm{~mL} \text { methanol } \\
2 \times 4 \mathrm{~mL} \text { water }\end{array}$ & $\begin{array}{l}5 \mathrm{~mL} \text { methanol } \\
5 \mathrm{~mL} \text { water }\end{array}$ & $\begin{array}{c}2 \times 2.5 \mathrm{~mL} \text { acetone } \\
2 \times 2.5 \mathrm{~mL} \text { methanol } \\
2 \times 5 \mathrm{~mL} \text { water }\end{array}$ & $\begin{array}{c}3 \times 2 \mathrm{~mL} \text { hexane } \\
2 \mathrm{~mL} \text { acetone } \\
3 \times 2 \mathrm{~mL} \text { methanol }\end{array}$ & $\begin{array}{l}3 \mathrm{~mL} \text { methanol } \\
3 \mathrm{~mL} \text { water }\end{array}$ \\
\hline pH of estrogens standard solutions & 3 & 2 & 5 & 3 & 2 \\
\hline Washing step & $\begin{array}{l}2 \times 5 \mathrm{~mL} \text { methanol:water }(1: 1) \\
2 \times 5 \mathrm{~mL} \text { acetone:water }(1: 2)\end{array}$ & $5 \mathrm{~mL}$ water & $25 \mathrm{~mL}$ hexane and water $(1: 4)$ & $5 \times 2 \mathrm{~mL}$ water & $2 \times 10 \mathrm{~mL}$ water \\
\hline Elution & $2 \times 4.5 \mathrm{~mL}$ methanol & $\begin{array}{l}10 \mathrm{~mL} \text { aceto- } \\
\text { nitrile }\end{array}$ & $2 \times 10 \mathrm{~mL}$ acetone & $4 \times 1 \mathrm{~mL}$ acetone & $20 \mathrm{~mL}$ methanol \\
\hline Complete dryness of solvents & Vacuum & Vacuum & Vacuum & Vacuum & Vacuum \\
\hline Redissolution of estrogens & $2 \mathrm{~mL}$ methanol & $2 \mathrm{~mL}$ acetonitrile & $2 \mathrm{~mL}$ methanol & $2 \mathrm{~mL}$ methanol & $2 \mathrm{~mL}$ methanol \\
\hline
\end{tabular}

Table 1: SPE methods for concentrating estrogens using standards of $20.00 \mu \mathrm{g} \mathrm{L}^{-1}$ of each compound.

\begin{tabular}{|c|c|c|c|c|c|}
\hline Recoveries \% & Method 1 & Method 2 & Method 3 & Method 4 & Method 5 \\
\hline Estrone (E1) & $25-35$ & $100-120$ & $60-70$ & $40-50$ & $120-140$ \\
\hline RSD \% & 23.5 & 12.8 & 10.8 & 15.7 & 10.8 \\
\hline Estradiol (E2) & $26.1-33$ & $85-110$ & $61-68$ & $41.5-49.2$ & $110-135$ \\
\hline RSD \% & 16.5 & 18.1 & 7.6 & 17.0 & 14.3 \\
\hline Estriol (E3) & $25.2-29$ & $89.8-110$ & $65-70$ & $42-49$ & $111-135$ \\
\hline RSD $\%$ & 9.9 & 14.2 & 5.2 & 10.8 & 13.7 \\
\hline $17 \alpha$-ethinylestradiol (EE2) & $27-34.5$ & $90-120$ & $64.2-70$ & $45-49$ & $121-138$ \\
\hline RSD $\%$ & 17.2 & 18.2 & 6.1 & 6.0 & 9.28 \\
\hline
\end{tabular}

Table 2: Recoveries of SPE procedure for target estrogens using standards with a concentration of $20.00 \mu g L^{-1}(n=3)$.

\begin{tabular}{|c|c|c|c|c|c|c|c|c|c|}
\hline Matrix & Concentrations tested & \multicolumn{2}{|c|}{ Estrone } & \multicolumn{2}{|c|}{ Estradiol } & \multicolumn{2}{|c|}{$17 \alpha$-ethinylestradiol } & Estriol & RSD (\%) \\
\hline \multirow{4}{*}{$\begin{array}{l}\text { Distilled Water } \\
\text { sample }\end{array}$} & $20 \mu \mathrm{g} \mathrm{L}-1$ & 110 & 0.3 & 115 & 0.42 & 116 & 0.65 & 101 & 1.47 \\
\hline & $10 \mu \mathrm{g} \mathrm{L}-1$ & 110 & 0.06 & 111 & 0.79 & 120 & 0.72 & 97 & 0.05 \\
\hline & $1 \mu g \mathrm{~L}-1$ & 115 & 1.02 & 106 & 0.06 & 110 & 1.32 & 85 & 0.10 \\
\hline & Correlation coefficients & \multicolumn{2}{|c|}{0.9977} & \multicolumn{2}{|c|}{0.9993} & \multicolumn{2}{|c|}{0.9993} & \multicolumn{2}{|c|}{0.9998} \\
\hline
\end{tabular}

Table 3: Recovery data for target estrogens in distilled water after SPE at different initial concentrations $(n=3)$. 
Citation: Fonseca AP, Cardoso M, Esteves V (2013) Determination of Estrogens in Raw and Treated Wastewater by High-Performance Liquid Chromatography-Ultraviolet Detection. J Environ Anal Toxicol 4: 203. doi: 10.4172/2161-0525.1000203

Page 4 of 5

estrogen detected, samples were spiked with a known concentration $\left(1 \mu \mathrm{g} \mathrm{L}{ }^{-1}\right)$ of the four target estrogens. All the samples were reanalysed to evaluate the increase of peaks area, and calculated the difference between the first and second area (sample and spiked sample).

The estrogen more frequently detected in raw wastewater's of all WWTP's were EE2 and E3 (bellow LOD), but in treated wastewater's the highest concentration was E1 (Figure 3). As expected natural estrogens and synthetic contraceptive estrogen, were identified in WWTP's raw wastewaters who serve more people. Their presence may be explained because tested raw wastewaters contain urban discharge where these estrogens are certainly present as consequence of human excretion.

The presence of EE2 in treated wastewaters is of particular interest as it exhibits toxicity at low nanogram per liter levels [20]. E1 and E2 are the most abundant estrogen founded in treated wastewater's, but only in plants serving more people.

So, the occurrence of E1, E2 and EE2 on treated wastewater's plants may be the result of incomplete removal of these compounds during

\begin{tabular}{|c|c|c|c|c|c|c|c|c|c|c|c|c|c|c|c|c|c|c|}
\hline \multirow{5}{*}{$\begin{array}{l}\text { Estrogens } \\
\text { concentra- } \\
\text { tions }\end{array}$} & \multirow{2}{*}{\multicolumn{2}{|c|}{$\begin{array}{l}\text { WWTP } 1 \\
\text { Jan-Mar }\end{array}$}} & \multicolumn{2}{|c|}{ WWTP 8} & \multicolumn{2}{|c|}{ WWTP 9} & \multicolumn{2}{|c|}{ WWTP 3} & \multicolumn{2}{|c|}{ WWTP 6} & \multicolumn{2}{|c|}{ WWTP 7} & \multicolumn{2}{|c|}{ WWTP 5} & $\begin{array}{c}\text { WWTP } \\
2\end{array}$ & & \multicolumn{2}{|c|}{ WWTP 4} \\
\hline & & & \multicolumn{2}{|c|}{ Jan-Mar } & \multicolumn{2}{|c|}{ Jun-Aug } & \multicolumn{2}{|c|}{ Feb-Apr } & \multicolumn{2}{|c|}{ Feb-Apr } & \multicolumn{2}{|c|}{ Jun-Aug } & \multicolumn{2}{|c|}{ Apr-Jun } & \multicolumn{2}{|c|}{ Oct-Dec } & \multicolumn{2}{|c|}{ Apr-Jun } \\
\hline & \multicolumn{18}{|c|}{ Number of people served by each WWTP } \\
\hline & \multicolumn{2}{|c|}{3000} & \multicolumn{2}{|c|}{3000} & \multicolumn{2}{|c|}{3145} & \multicolumn{2}{|c|}{5000} & \multicolumn{2}{|c|}{6000} & \multicolumn{2}{|c|}{20500} & \multicolumn{2}{|c|}{50000} & \multicolumn{2}{|c|}{180000} & \multicolumn{2}{|c|}{203202} \\
\hline & IIn & IIn & OOut & IIn & IIn & OOut & IIn & OOut & IIn & OOut & IIn & OOut & IIn & OOut & IIn & OOut & IIn & OOut \\
\hline $\mathrm{E} 3\left(\mu \mathrm{g} \mathrm{L}^{-1}\right)$ & 0.24 & 0.15 & 0 & 0.15 & 0 & 0 & 00,25 & 0 & 0.16 & 0 & 0.15 & 0 & 0.14 & 0 & 0.24 & 0.12 & 0 & 0 \\
\hline SD & $0 \pm 0.01$ & \pm \pm 0.02 & 0 & \pm \pm 0.02 & 0 & 0 & \pm \pm 0.03 & 0 & \pm \pm 0.04 & 0 & \pm \pm 0.02 & 0 & \pm \pm 0.01 & 0 & \pm \pm 0.02 & \pm \pm 0.02 & 0 & 0 \\
\hline $\mathrm{E} 2\left(\mu \mathrm{g} \mathrm{L}^{-1}\right)$ & 0 & 0 & 0 & 0 & 0 & 0 & 0 & 0 & .0 .25 & 0.19 & 0 & 0 & 0 & 0 & 0 & 0 & 0.14 & 0.1 \\
\hline SD & 0 & 0 & 0 & 0 & 0 & 0 & 0 & 0 & \pm \pm 0.02 & \pm \pm 0.03 & 0 & 0 & 0 & 0 & 0 & 0 & \pm \pm 0.03 & \pm \pm 0.01 \\
\hline $\mathrm{EE} 2\left(\mu \mathrm{L} \mathrm{L}^{-1}\right)$ & 0.13 & 0.14 & 0 & 0.14 & 0 & 0 & 00,16 & 0 & 0.19 & 0 & 0.14 & 0 & 0.18 & 0 & 0.15 & 0.12 & 0.14 & 0 \\
\hline SD & \pm \pm 0.01 & \pm \pm 0.03 & 0 & \pm \pm 0.03 & 0 & 0 & \pm \pm 0.02 & 0 & \pm \pm 0.02 & 0 & \pm \pm 0.03 & 0 & \pm \pm 0.02 & 0 & \pm \pm 0.02 & \pm \pm 0.02 & \pm \pm 0.06 & 0 \\
\hline $\mathrm{E} 1\left(\mu \mathrm{g} \mathrm{L}^{-1}\right)$ & 0 & 0 & 0 & 0 & 0 & 0 & 0.23 & 0.16 & 0.16 & 0.15 & 0 & 0 & 0 & 0 & 0 & 0 & 0.72 & 0.25 \\
\hline SD & 0 & 0 & 0 & 0 & 0 & 0 & \pm \pm 0.02 & \pm \pm 0.01 & \pm \pm 0.04 & \pm \pm 0.02 & 0 & 0 & 0 & 0 & 0 & 0 & \pm \pm 0.12 & \pm \pm 0.02 \\
\hline
\end{tabular}

Table 4: Occurrence of selected estrogens concentrations, expressed in $\mu \mathrm{g}$ per liter $(n=3)$, in raw wastewater's WWTP's raw wastewater's and treated wastewater's of nine plants investigated.

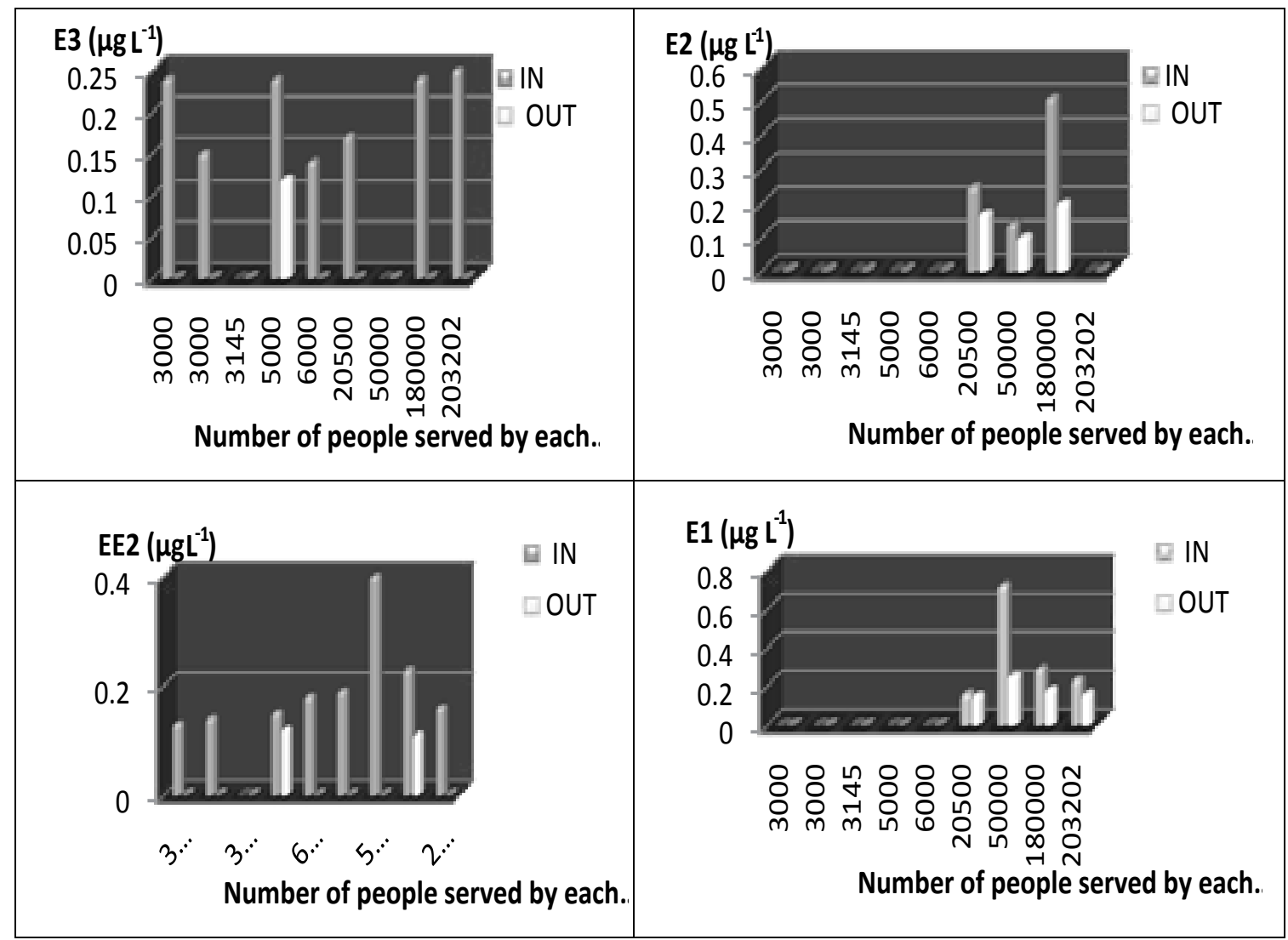

Figure 3: Graphics of each estrogen vs. raw wastewater and treated wastewater of nine different WWTP's. 
Citation: Fonseca AP, Cardoso M, Esteves V (2013) Determination of Estrogens in Raw and Treated Wastewater by High-Performance Liquid Chromatography-Ultraviolet Detection. J Environ Anal Toxicol 4: 203. doi: 10.4172/2161-0525.1000203

treatment or release of the active estrogenic forms from conjugates during the same treatment process $[20,21]$.

\section{Conclusions}

Most current WWTP's are not really designed to treat organic contaminants and a high part of emerging compounds and their metabolites may escape elimination in WWTP's and enter the aquatic environment via sewage treated wastewaters. The natural estrogens as well as the contraceptive estrogen were frequently detected in WWTP's discharges, due to their incomplete removal during the treatment of waste water [6,16-19].

In this study, an optimization of the analytical method based on a SPE-HPLC procedure with UV detection has been developed for the simultaneous determination of estrogens in waste water samples.

Five different SPE methods were tested, with standards, for the optimization of SPE procedure. For the chosen method, standards were used for recovery evaluation, with results ranging 100 to $120 \%$ for E1, 85 to $110 \%$ for E2, 90 to $120 \%$ for EE2 and 89.8 to $110 \%$ for E3.

These results confirm that SPE-HPLC method is therefore considered to be suitable for the application in environmental water samples. The optimized method was used for the determination of all targeted estrogens in all raw wastewater's and treated wastewater's wastes water samples.

All the compounds that were selected in the study were found in raw wastewaters and treated wastewaters in concentrations varying in the microgram per liter range, indicating a permanent enter in rivers, where these treated waters are always discharged.

General raw wastewater's estrogens concentrations are in the ranged from 0.14 to $0.51 \mu \mathrm{g} \mathrm{L}^{-1}$ for estradiol, 0.13 to $0.23 \mu \mathrm{g} \mathrm{L}^{-1}$ for ethinylestradiol and 0.16 to $0.72 \mu \mathrm{g} \mathrm{L}^{-1}$ for estrone. Treated wastewater's estrogens concentrations are in the ranged from 0.10 to $0.20 \mu \mathrm{g} \mathrm{L}^{-1}$ for estradiol, 0.11 to $0.19 \mu \mathrm{g} \mathrm{L}^{-1}$ for ethinylestradiol and 0.15 to $0.25 \mu \mathrm{g} \mathrm{L}^{-1}$ for estrone. These results are similar when compared to values obtained in other countries, such as Germany, Italy and Netherlands [11,22-24].

The results show that the studied estrogens can be simultaneous separated and determined from waste water samples by the proposed method with satisfactory accuracy and precision. We think it should be a systematic monitoring in the determination of estrogens in all WWTP's, who serving people, in a public health issue and as a future work.

\section{References}

1. Ying GG, Kookana RS, Ru YJ (2002) Occurrence and fate of hormone steroids in the environment. Environ Int 28: 545-551.

2. Kidd KA, Blanchfield PJ, Mills KH, Palace VP, Evans RE, et al. (2007) Collapse of a fish population after exposure to a synthetic estrogen. P Natl Acad Sci USA 104: 8897-8901.

3. Vethaak AD, Rijs GBJ, Schrap SM, Ruiter H, Gerritsen A, et al. (2002) Management and Waster WaterTreatment RIZA/RIKZ-report no. 2002.001.

4. Belfroid AC, Van Der Horst A, Vethaak AD, Schäfer AJ, Rijs GBJ, et al. (1999) Analysis and occurrence of oestrogenic hormones and their glucuronides in sur face water and waste water in the Netherlands. Sci Total Environ 225: 101-108.

5. Zhang ZL, Hibberd A, Zhou JL (2006) Optimization of derivatisation for the analysis of estrogenic compounds in water by solid-phase extraction gas chromatography- mass spectrometry. Analytica Chimica Acta 577: 52-61.

6. Yan W, Feng Q, Wei Y, Lin JM (2009) Simultaneous Determination of Ten Estrogens and their Metabolites in Waters by Improved Two-Step SPE Followed by LC-MS. Chromatographia 69: 621-628.
7. Ternes TA, Kreckel P, Mueller J (1999) Behaviour and occurrence of estrogens in municipal sewage treatment plants-II. Aerobic batch experiments with activated sludge. Sci. Total Environ 225: 91-99.

8. Solé M, Barceló D, Porte C (2002) Seasonal variation of plasmatic and hepatic vitellogenin and EROD activity in carp, Cyprinus carpio, in relation to sewage treatment plants. Aquatic Toxicology 60: 233-248.

9. Noppe H, De Wasch K, Poelmans S, Van Hoof N, Verslycke T, et al. (2005) Development and validation of an analytical method for detection of estrogens in water. Anal Bioanal Chem 382: 91.

10. Park IS, Kim JH, Cho SH, Kim DS (2004) Sex differentiation and hormonal sex reversal in the bagrid catfish Pseudobagrus fulvidraco. Aquaculture 232 183-193.

11. Wang S, Xu Z (2008) Separation and determination of estrone in environmental and drinking water using molecularly imprinted solid phase extraction coupled with HPLC. Journal of Separation Science 30: 1181-1188.

12. Kitamura K, Miyajima K, Higashitani T, Nakada N, Komori K, et al. (2009) The effect of estrogens in river water and treated wastewater on feminization of Japanese medaka. Journal of the American Water Resources Association 45: 22-34.

13. Díaz M, Luiz M, Alegretti P, Furlong J, Amat-Guerri F et al. (2009) Visible-lightmediated photodegradation of $17 \beta$-estradiol: Kinetics, mechanism and Water Air Soil Pollut photoproducts. J Photochem Photobiol 202: 221.

14. Penalver A, Pocurull E, Borrull F, Marce RM (2002) Method based on solidphase microextraction--high-performance liquid chromatography with UV and electrochemical detection to determine estrogenic compounds in water samples. J Chromatogr A 964: 153-160.

15. Stafiej A, Pyrznska K, Regan F (2007) Determination of anti-inflammatory drugs and estrogens in water by HPLC with UV detection. J Sep Sci 30: 985-991.

16. Miller J, Miller J (2005) Statistics and chemometrics for analytical chemistry. 5th edn, Harlow (England): Prentice Hall 268.

17. Sarmah AK, Northcott GL, Leusch F, Tremblay L (2006) A survey of endocrine disrupting chemicals (EDCs) in municipal sewage and animal waste effluents in the Waikato region of New Zealand. Science of the Total Environment 355: 135- 144.

18. Vulliet E, Baugros JB, Flament-Waton MM, Grenier-Loustalot MF (2007) Analytical methods for the determination of selected steroid sex hormones and corticosteriods in wastewater. Anal Bioanal Chem 387: 2143-2151.

19. Laganàa A, Bacalonia A, De Levaa I, Faberia A, Fagoa G, et al. (2004) Analytical methodologies for determining the occurrence of endocrine disrupting chemicals in sewage treatment plants and natural waters. Analytica Chimica Acta 501: 79-88.

20. Johnson AC, Sumpter JP (2001) Removal of endocrine-disrupting chemicals in activated sludge treatment works. Environ Sci Technol 35: 4697-4703.

21. Lopez de Alda MJ, Barceló DJ (2001) Use of SPE in various of its modalities for sample preparation in the determination of estrogens and progestogens in sediment and water. Chromatogr A 938: 145-153.

22. Johnson AC, Belfroid A, Di Corcia A (2000) Estimating steroid oestrogen inputs into activated sludge treatment works and observations on their removal from the effluent. Sci. Total Environ 256: 163-173.

23. Baronti C, Curini R, D'Ascenzo G, Di Corcia A, Gentili A, et al. (2000) Monitoring natural and synthetic estrogens at activated sludge sewage treatment plants and in a receiving river water. Environ Sci Technol 34: 5059-5066.

24. Streck G (2009) Chemical and biological analysis of estrogenic, progestagenic and androgenic steroids in the environment. Trends in Analytical Chemistry 28 $635-652$. 